\title{
Tropical and Subtropical Fruits: Postharvest Biology and Storage
}

\author{
Shifeng Cao $\mathbb{D},{ }^{1}$ Zhenfeng Yang, ${ }^{2}$ and Sunil Pareek $\mathbb{D}^{3}$ \\ ${ }^{1}$ School of Agriculture, Food and Wine, The University of Adelaide, PMB 1, Glen Osmond, SA 5064, Australia \\ ${ }^{2}$ College of Biological and Environmental Sciences, Zhejiang Wanli University, Ningbo 315100, China \\ ${ }^{3}$ National Institute of Food Technology Entrepreneurship and Management, Kundli, Sonepat 131028, India \\ Correspondence should be addressed to Shifeng Cao; shifengcao1@gmail.com
}

Received 17 April 2018; Accepted 17 April 2018; Published 9 May 2018

Copyright (c) 2018 Shifeng Cao et al. This is an open access article distributed under the Creative Commons Attribution License, which permits unrestricted use, distribution, and reproduction in any medium, provided the original work is properly cited.

This special issue is focused on the factors involved in ripening, senescence, and deterioration of harvested tropical and subtropical fruits and the postharvest technologies to restrict loss and ensure the maximum quality value.

Banana is one of the major commercial fruit crops grown in tropics and subtropics. It is very susceptible to mechanical damage during harvesting, handling, packaging, and transportation, which results in a substantial reduction in quality. Phospholipase D (PLD) is an important enzyme that initiates membrane phospholipid degradation during ripening, senescence, and signal transduction that takes place in response to hormones and environmental stresses. Li et al. clone one $\operatorname{PLD} \alpha$ gene from banana fruit, which shows an increasing trend during fruit ripening, thereby leading to the damage of cell-membrane integrity and senescence of postharvest bananas. Then, they continue their PLD research and focus their paper on its response to mechanical wounding in postharvest banana fruit, which provides basic knowledge for further investigating the mechanism of postharvest banana adapting to environmental stresses.

Longan, litchi, and rambutan are typical subtropical fruit opulently cultivated in southern China, which are popular for customers to buy in summer. However, due to cellmembrane lipid peroxidation and polyphenol oxidation, the inherent perishability of these fruit has been considered as a serious problem, resulting in fruit browning or fungal infection in the first week after harvested from orchard, which greatly impairs economic chain of fruit agriculture. $\mathrm{Li}$ et al. report that both refrigeration and UV-C exposure can extend the shelf life of the three fruit.

Mangosteen is popularly grown in Southeast Asia. During on-tree maturation of mangosteen fruit, rainfall frequently induces more translucent flesh disorder developing in ripe fruit. Translucent disorder, translucency, and a litter bit crispy texture, is an abnormal ripening process that occurs at the largest segment of aril. This disorder makes a serious problem for mangosteen grower from the past until now. Noichinda et al. present a research article on this disorder and find that the capillary water in fruit pericarp is one of the reasons in mangosteen aril.

Apricots are popular worldwide owing to their high nutritional value and delicious flavor, which not only can be used as fresh fruit but also has a high importance as processed product. Refrigeration is widely used to delay ripening and control fruit decay, but apricot is a cold-sensitive fruit and is subject to defects at low temperature. Jing et al. discuss the effects of different harvest maturity on the incidence of chilling injury and storage quality of apricots and provide a theoretical reference to the suitable harvest maturity of this fruit.

Each tropical and subtropical fruit possesses unique characteristics expressed in appearance and flavor and sometimes in its growth habit. Decay and quality deterioration are the major postharvest problems when the fruit are stored at ambient temperatures. Low temperature storage is an effective method to retard ripening and senescence; however, many tropical and subtropical fruit will develop chilling injury and be sensitive to fungal invasion. Therefore, better understanding of postharvest physiology of tropical and subtropical fruit and the development of adequate postharvest technologies are vital for successful handling and long distance transport. It is certainly worth investigating improved procedures for storage and ripening that would allow preconditioned, ripening-initiated, 
ready-to-eat fruit to be offered to consumers. Genetic transformation to manipulate the progression and uniformity of ripening, disease resistance, and senescence may be also a helpful strategy.

Shifeng Cao Zhenfeng Yang Sunil Pareek 


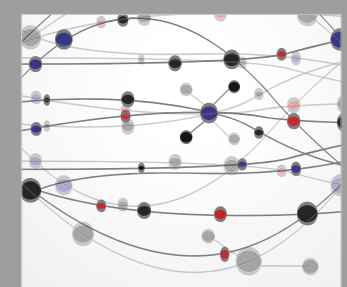

The Scientific World Journal
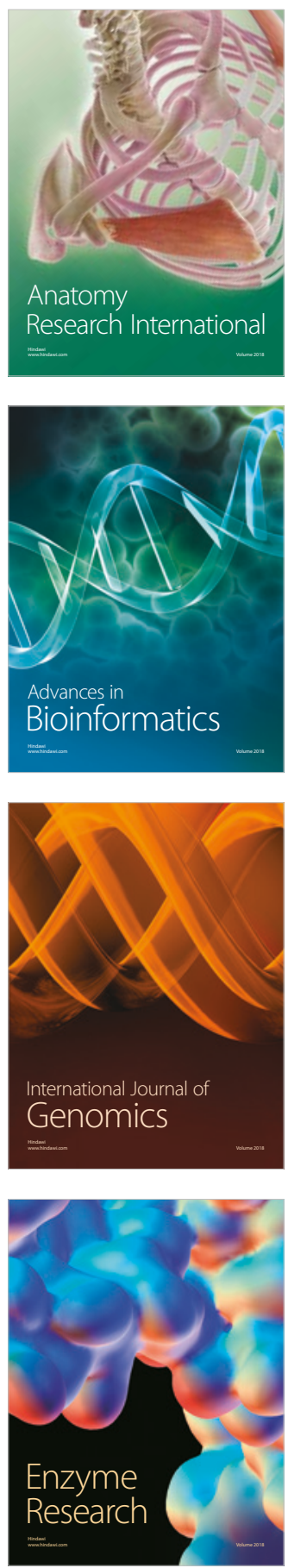
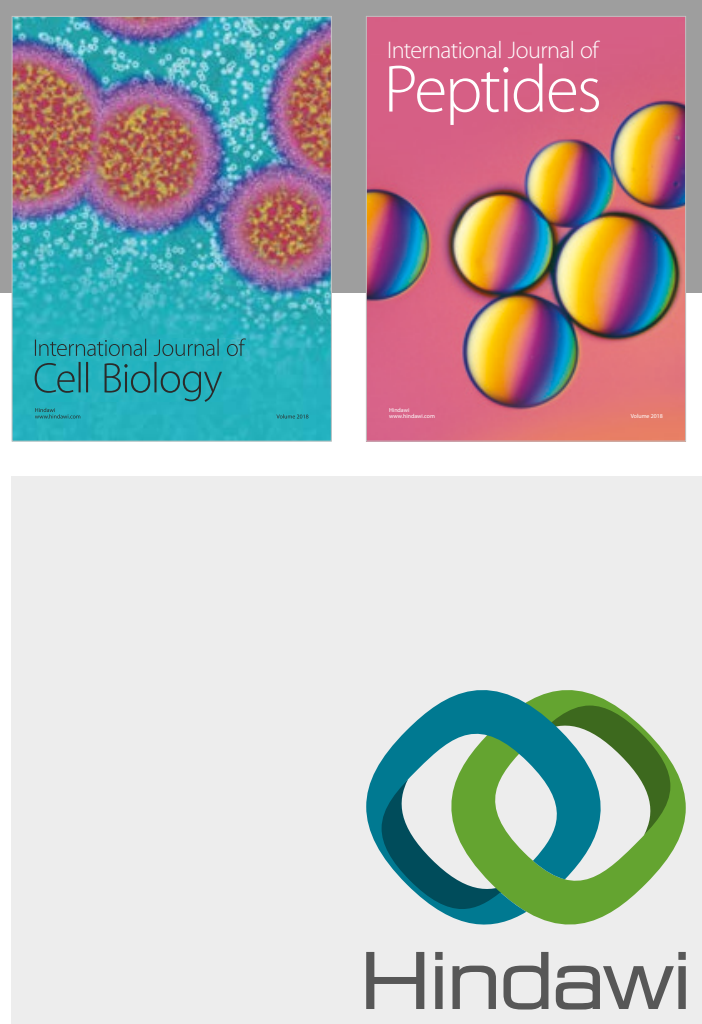

Submit your manuscripts at

www.hindawi.com
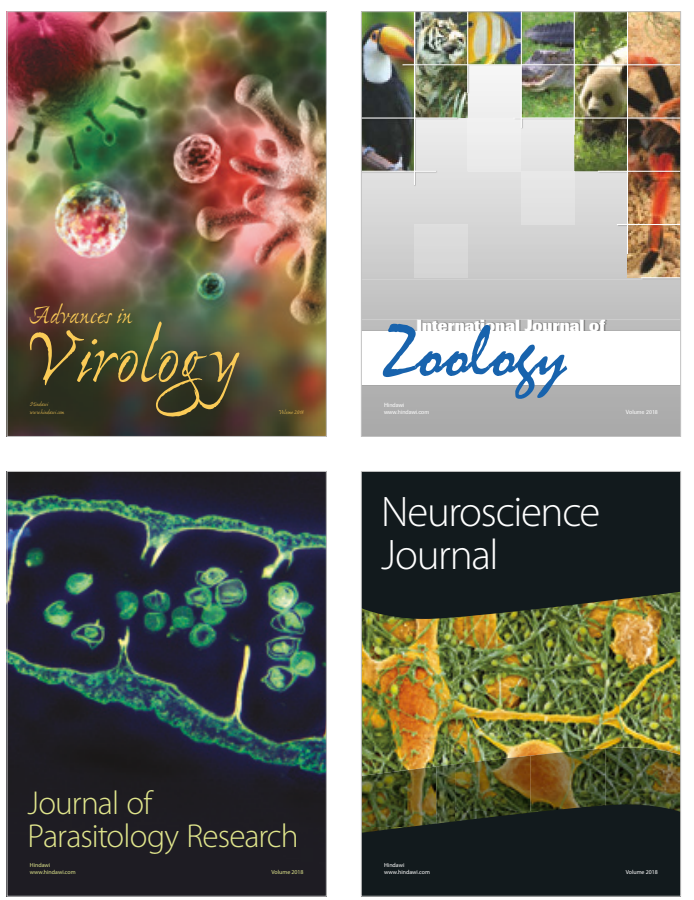
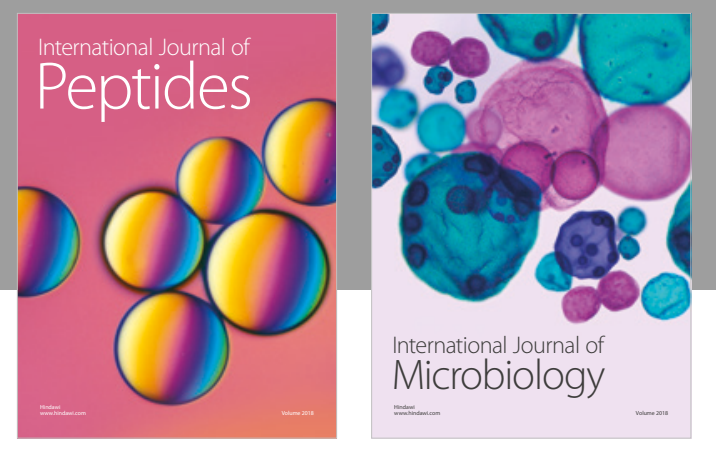

nternational Journal of Microbiology
Journal of
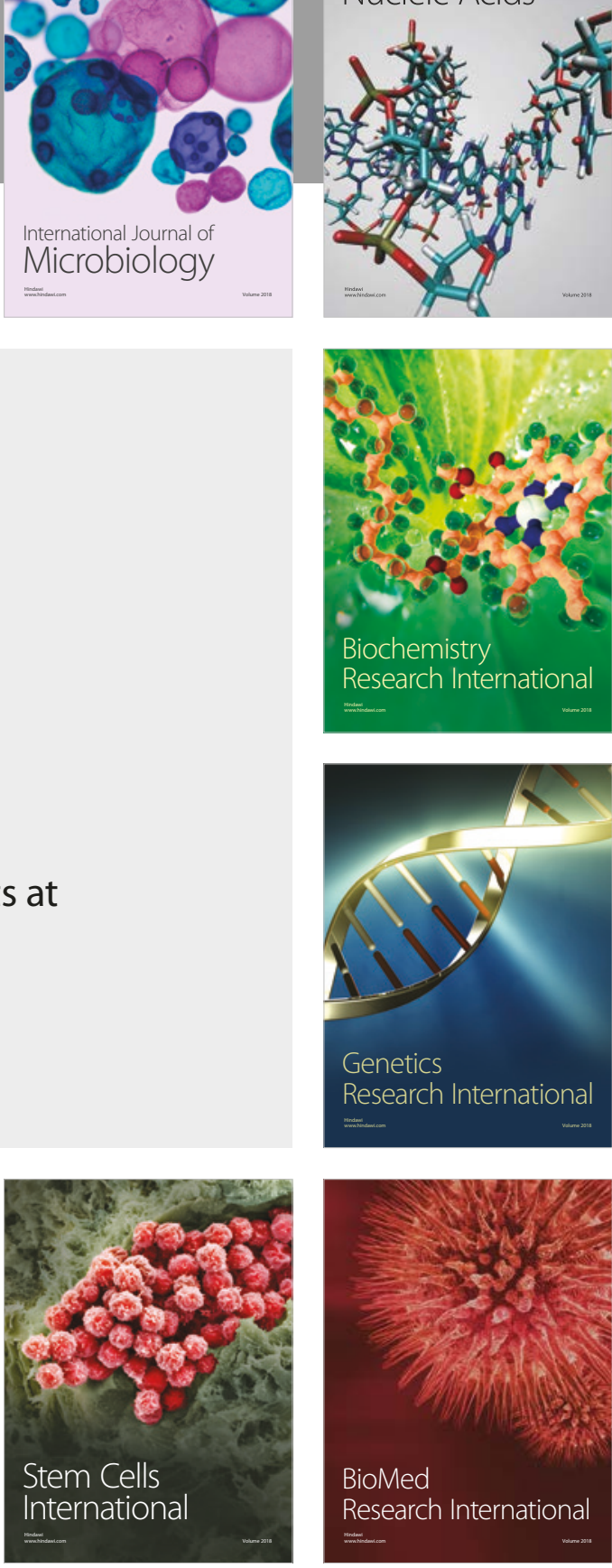
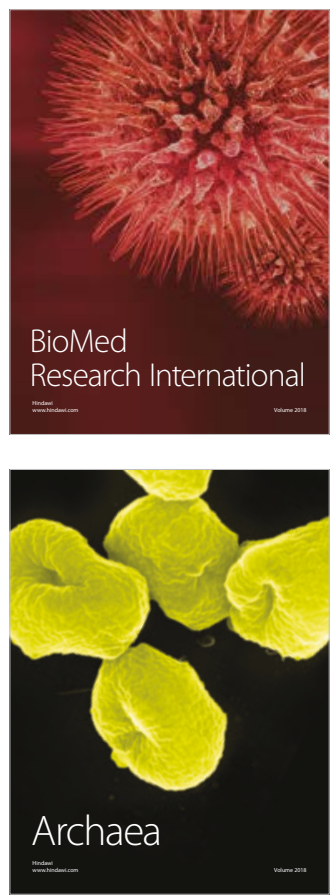